\title{
Multi-variable mathematical models for the air-cathode microbial fuel cell system
}

\author{
Shiqi Ou ${ }^{1}$, Hiroyuki Kashima ${ }^{2}$, Douglas S. Aaron ${ }^{1}$, John M. Regan ${ }^{2}$, Matthew M. Mench ${ }^{1}$ \\ ${ }^{1}$ Department of Mechanical, Aerospace and Biomedical Engineering, the University of Tennessee, USA; \\ ${ }^{2}$ Department of Civil \& Environmental Engineering, Penn State University, USA.
}

\begin{abstract}
This research adopted the version control system into the model construction for the single chamber air-cathode microbial fuel cell (MFC) system, the work was open to track and able to be modified by further subroutines and equations and to understand the interrelation of biological, chemical, and electrochemical reactions. The anodic steady state model was used to consider the chemical species diffusion and electric migration influence to the MFC performance. In the cathodic steady state model, the mass transport and reactions in a multi-layer, abiotic cathode and multi-bacteria cathode biofilm were simulated. Transport of hydroxide was assumed for cathodic $\mathrm{pH}$ change. This assumption, as employed, is as an alternative to the typical notion of proton consumption during oxygen reduction to explain elevated cathode $\mathrm{pH}$. The cathodic steady state model provided the power density and polarization curve performance results that can be compared to an experimental MFC system. Another aspect considered was the relative contributions of platinum catalyst and microbes on the cathode to the oxygen reduction reaction (ORR). Simulation results showed that the biocatalyst in a cathode that includes a Pt/C catalyst plays a minor role in ORR, contributing up to $8 \%$ of the total power calculated by the models.
\end{abstract}

\section{Keywords:}

Microbial fuel cell; computational simulation; cathode limitations; catalyst; mass transport; electrochemical reactions. 
* Corresponding author at: Electrochemical Energy Storage and Conversion Laboratory, Department of Mechanical, Aerospace, and Biomedical Engineering, The University of Tennessee, Knoxville, TN 37996, USA. Tel.: +1 (865)974 6751.

E-mail address: mmench@utk.edu (M.M. Mench). 


\section{Introduction}

The microbial fuel cell (MFC) is a bioelectrochemical system that is able to generate electrical current via exoelectrogens, biomass capable of transporting electrons outside their cell walls [1]. Responses of the bioelectrochemical mechanisms in MFCs must be understood to design MFCs with increased current and power output via optimized materials, transport, kinetics, and architecture. The single chamber air-cathode MFC is a simple structure conducive to scale-up and can generate relatively high power because of its lower internal resistance compared with other MFC designs such as the two chamber MFC reactor [1]. An added benefit to this design is reduced cost since no ion exchange membrane is necessary. These benefits prompted selection of the single chamber air-cathode MFC as the subject for the experiments and modeling in this work.

Computational modeling has been utilized for the MFC analysis in specific regions, such as the biofilm growth on the anode [2] or the electrochemical reactions in MFC [3]. Initial MFC models included the simulations of steady-state biofilm growth, multi-factor transient mixedculture states of electrochemical reactions, and bacterial growth processes [4, 5]. Wanner [5] highlights the complex, transient, 1-D microbial biofilm growth process dependent on nutrient consumption, multispecies competition, and electrode materials. Biofilm simulation becomes more complex when considering the biofilm liquid phase volume fraction, detachment and attachment of cells and particles, and the mass transport of dissolved components in bulk liquid and biofilm [6]. In addition, the local electrical potential and the proton/hydroxide transport are important to MFC system behavior. Bacterial growth in MFC systems does not only depend on nutrient concentration but also the local electrical potential and $\mathrm{pH}$ environment. Models become increasingly complex when the anode and cathode are comprehensively considered in the case of 
regional or half-cell simulation (Steady state or transient MFC models focused on the anode local mass transport or electrochemical performance, the intricate cathodic reactions were usually simplified to an ORR, and mass transport in cathodic materials was neglected in the full cell system simulations.), resulting in few published full cell models [2, 3].

Cathode performance is rarely simulated in MFC models, though the cathode reactions have experimentally been shown to limit the overall power generation in many MFC systems [7-10]. In the air-cathode systems, oxygen functions as the electron acceptor and is reduced at the cathode, typically on a Pt/C catalyst. The cathodic biofilm has also been found to play a role in catalyzing the cathodic reduction reactions, though its significance in catalyzing the ORRs is still unclear from the experiments [11]. Recent results $[8,9]$ suggest that the ORR in an MFC cathode is not the same as found in a polymer electrolyte fuel cell [12]. The ORR in the polymer electrolyte fuel cell is shown in Eqn. (1):

$$
0.25 \mathrm{O}_{2}+\mathrm{e}^{-}+\mathrm{H}^{+} \rightarrow 0.5 \mathrm{H}_{2} \mathrm{O}
$$

However, MFC cathodes have been found to follow the ORR described in the Eqn. (2) $[8,9]$, which was adopted that hydroxide ions govern potential losses in the cathode catalyst layer.

$$
0.25 \mathrm{O}_{2}+\mathrm{e}^{-}+0.5 \mathrm{H}_{2} \mathrm{O} \rightarrow \mathrm{OH}^{-} \quad \mathrm{E}^{0}=+0.40 \mathrm{~V}
$$

Biofilm growth at the cathodic surface is also an influential factor affecting the distribution of hydroxide and other ions [9], and the resultant $\mathrm{pH}$ strongly influences the Pt-catalyzed oxygen reduction, microbial growth, and overall power generation [13]. A complicating feature of the cathode is that the abiotic regions of the air-cathode structure are made of multiple layers and materials instead of a homogeneous layer. The material and structure in the cathode affect the gas phase and liquid phase mass transport through the cathode, impacting the whole system 
performance [10]. Thus, hydroxide and oxygen transport in the cathode are important considerations in MFC cathode models.

In this paper, a series of MFC models was developed for the anode and cathode in the MFC reactor. The simulation procedures, electrochemical reactions and numerical methods that couple the multiple parameters in the anode and cathode were established separately. The anode halfcell model is presented to discuss MFC performance as influenced by electric migration in the mass transport governing equation. Primary considerations for the cathode half-cell model include cathodic mass transport via simulating the hydroxide effects on the ORR, the contribution of the Pt/C catalyst layer (designated "metal catalyst" [11] to distinguish from the biocatalyst in the cathode biomass) on the ORR, and the cathode biofilm effects on $\mathrm{pH}$ distribution, oxygen utilization, and potential cathode oxidation. This work will provide a foundation for future model development of a full-cell MFC system. 


\section{Model Formulation}

The control version system GIT was used to develop subroutines and sub-models in the following research into the model system. The GIT tracks model development, allowing versions over time to be compared, which aided both steady state and transient models. The general procedure for the mode development in MFC system was: a) adopt reasonable assumptions based on physical structure and materials; b) analyze electron transfer, dependent on mass transport; c) derive the mathematical electrochemical/biological equations and build the mass transport governing equations; d) adopt appropriate numerical methods for simulations. The electrochemical equations and the transport expressions were initially developed for the anodic model; GIT then allowed these relationships to readily be adapted for application to the cathode model.

Anode Assumptions. The microorganisms were batch-fed a pH-buffered medium containing 1.0 g/L sodium acetate as the sole electron donor. Suspended bacteria growth in the bulk liquid was neglected in the model. The system coulombic efficiency changes with time as the biofilm grows and develops, and has been reported over a large range from $0.04 \%$ to $97 \%$ [14]; a constant anodic coulombic efficiency of $80 \%$ was assumed here to simplify the stoichiometric relations for anode biofilm growth. Therefore, $20 \%$ of acetate-derived electrons were consumed by the anode-respiring bacteria (ARB) for endogenous respiration and new biomass growth, while the remaining $80 \%$ were conducted directly to the anode through the extracellular polymeric substances (EPS) and exoelectrogens. The overall microbial fuel cell was a $4 \times 4 \times 4 \mathrm{~cm}$ cubic reactor. The anodic biofilm was assumed to be fully grown with a constant thickness of 0.025 $\mathrm{mm}$ in the steady state model. The initial acetate concentration in the half-cell model and the acetate concentration on the liquid side boundary were $1.0 \mathrm{~g} / \mathrm{L}$. In this anode half-cell model, the 
cathodic potential was fixed so the influence from the cathodic electrochemical changes was neglected in the calculations.

Anode Steady State Model. The anode structure was divided into three domains that include: anode metal (as current collector), the anode electrode (biofilm support and electron conductor), and biofilm. While graphite fiber brushes and carbon paper are two commonly used anode materials in MFCs [1], the anode was approximated as a planar surface. Fig. 1 is a schematic of the anode region.

The comprehensive equation for the anodic biological acetate oxidation reaction is shown in the Eqn. (3). New biomass and protons are produced by this reaction. Electrons are conducted through the anodic biofilm into the anode. $[2,15]$

$$
\mathrm{CH}_{3} \mathrm{COO}^{-}+\mathrm{Y}_{\mathrm{N}} \mathrm{NH}_{4}^{+}+\mathrm{Y}_{\mathrm{W}} \mathrm{H}_{2} \mathrm{O} \rightarrow \mathrm{Y}_{\mathrm{X}} \mathrm{C}_{5} \mathrm{H}_{7} \mathrm{O}_{2} \mathrm{~N}+\mathrm{Y}_{\mathrm{Car}} \mathrm{HCO}_{3}^{-}+\mathrm{Y}_{\mathrm{e}} \mathrm{e}^{-}+\mathrm{Y}_{\mathrm{H}} \mathrm{H}^{+}
$$

where $Y_{X}$ was assumed to be $0.02\left(\mathrm{~g} \mathrm{ARB} / \mathrm{g}\right.$ acetate) [16], and $\mathrm{Y}_{\mathrm{H}}$ was $4.17 \times 10^{-5}\left(\mathrm{~mol} \mathrm{H}^{+} / \mathrm{g}\right.$ acetate). In the steady state model, the electrode current was known and the electron distribution was able to be calculated based on the electron balance [3]. The electronic conduction is described in the Eqn. (4) where $\mathrm{i}_{\mathrm{A}}$ is the anode current density $\left(\mathrm{A} / \mathrm{m}^{2}\right)$ distributed in every control volume, $\mathrm{F}$ is the Faraday constant $(\mathrm{C} / \mathrm{mol}), \mathrm{M}_{\mathrm{Ac}}$ and $\mathrm{M}_{\mathrm{ARB}}$ are the molar mass $(\mathrm{g} / \mathrm{mol})$ for acetate and $\mathrm{ARB}$ respectively, $\mathrm{Y}_{\mathrm{Ac}}\left(\mathrm{mol} \mathrm{e}^{-} / \mathrm{mol}\right.$ Acetate) and $\mathrm{Y}_{\mathrm{ARB}}\left(\mathrm{mol} \mathrm{e}^{-} / \mathrm{g} \mathrm{ARB}\right)$ are the electron equivalences $[3,11]$.

$$
0=\frac{\partial \mathrm{i}_{\mathrm{A}}}{\partial \mathrm{x}}+\frac{\mathrm{Y}_{\mathrm{Ac}} \mathrm{Fr}_{\mathrm{Ac}}}{\mathrm{M}_{\mathrm{Ac}}}+\mathrm{f} \frac{\mathrm{Y}_{\mathrm{ARB}} \mathrm{Fr}_{\mathrm{ARB}}}{\mathrm{M}_{\mathrm{ARB}}}
$$

where $\delta \mathrm{x}$ is the length of the control volume. The conductivity of the anodic biofilm $\sigma_{\mathrm{bio}, \mathrm{A}}$ was assumed to be $1.0 \times 10^{-2}(\mathrm{~S} / \mathrm{m})$; the distribution of the local potential $\left(\mathrm{E}_{\mathrm{A}}\right)$ and current density $\left(\mathrm{i}_{\mathrm{A}}\right)$ 
were able to be derived based on work described by Marcus et. al. 2010 [3]. According to the Nernst-Monod equation [17], the acetate utilization rate is described by the Eqn. (5).

$$
r_{A c}=-q_{A c, \max } c_{B} \frac{c_{A c}}{K_{A c}+c_{A c}} \frac{1}{1+\exp \left(-\frac{F}{R T}\left(\eta_{a c t, A}-\eta_{a c t, K A}\right)\right)}
$$

where $r_{A c}$ is acetate reaction rate $(\mathrm{mol} /(\mathrm{L} \cdot \mathrm{s})), \mathrm{q}_{\mathrm{Ac} \text {, max }}$ is the maximum specific rate of acetate utilization $\left(1.155 \times 10^{-5}\right.$ mol Acetate $/(\mathrm{g}$ biomass $\left.\cdot \mathrm{s})\right), \mathrm{c}_{\mathrm{B}}$ is the active ARB biomass concentration $(\mathrm{g} / \mathrm{L}), \quad \mathrm{c}_{\mathrm{Ac}}$ is the acetate concentration $(\mathrm{g} / \mathrm{L}), \mathrm{K}_{\mathrm{Ac}}$ is half-maximum-rate for the acetate concentration $(0.0025 \mathrm{~g} / \mathrm{L}), \eta_{\mathrm{act}, \mathrm{A}}$ is the anodic activation overpotential $(\mathrm{V})$, and $\eta_{\mathrm{act}, \mathrm{KA}}$ is the half-maximum-rate for the anodic activation overpotential (V). At the same time, the calculation of the anodic local concentration overpotential is presented in the Eqn. (6).

$$
\eta_{\text {con }, \mathrm{A}}=\left|\frac{\mathrm{RT}}{4 \mathrm{~F}} \lg \left(1-\frac{\mathrm{i}_{\mathrm{A}}}{\mathrm{i}_{\text {lim }}}\right)\right|+\left|\frac{\mathrm{RT}}{4 \mathrm{~F}} \lg \left(\frac{\mathrm{c}_{\mathrm{H}}}{\mathrm{c}_{\text {ini }}}\right)\right|
$$

where $\mathrm{T}$ is the temperature $(\mathrm{K}), \mathrm{i}_{\mathrm{lim}}$ is the anodic limiting current density (assumed to be 7.0 $\left.\mathrm{A} / \mathrm{m}^{2}\right), \mathrm{c}_{\mathrm{H}}$ is the proton concentration $(\mathrm{mM})$, and $\mathrm{c}_{\mathrm{ini}}$ is the initial proton concentration $(\mathrm{mM})$ in anode (the initial $\mathrm{pH}$ was assumed to be 7.2 in the model).

The transport of chemical components in the fluid involves diffusive and advective transport [18]. In an electrochemical-physical system, the ionic flux is also influenced by the electric field [19]. The mass transport equations for the charged chemical species in a fluid environment are thus sums of transport via the advection, concentration-driven diffusion, and electric fieldinduced migration; the resultant equation is called the Nernst-Planck equation. The advection term was not included in this model since the simulated reactor was operated in a batch mode with no stirring. The fluid flow was static and the velocity was assumed to be zero in this halfcell model. The resultant mass transport Nernst-Planck equation for a component is shown in the Eqn. (7). 


$$
\frac{\partial c_{i}}{\partial t}=-\frac{\partial}{\partial x}\left(F_{\text {diff }}+F_{\text {mig }}\right)+r_{i}
$$

The $\mathrm{F}_{\text {diff }}$ is the diffusion flux term:

$$
\mathrm{F}_{\text {diff }}=-\mathrm{D}_{\mathrm{i}} \frac{\partial \mathrm{c}_{\mathrm{i}}}{\partial \mathrm{x}}
$$

The $F_{\text {mig }}$ is the electric migration flux term [20]:

$$
F_{\text {mig }}=-\frac{z_{\mathrm{i}} \mathrm{F}}{\mathrm{RT}} \mathrm{D}_{\mathrm{i}}^{\mathrm{eff}} \frac{\partial \mathrm{E}_{\mathrm{A}}}{\partial \mathrm{x}}
$$

where $i$ is the charged chemical species, $c_{i}$ is the species concentration, $D_{i}^{\text {eff }}$ is the effective diffusion coefficient, $\mathrm{z}_{\mathrm{i}}$ is the charge of the ion, $\mathrm{E}_{\mathrm{A}}$ is the anodic electric potential $(\mathrm{V})$ and $\mathrm{r}_{\mathrm{i}}$ is the reaction rate. In the anode steady state model, the chemical substrate concentration varies across the layers (anodic boundary diffusion layer, anodic biofilm, carbon paper) in the anodic half-cell model. The effective diffusion coefficient in the porous media depends on the porosity [21], as shown in Eqn (10):

$$
D_{i}^{\text {eff }}=\theta D_{i}
$$

where $D_{i}$ is the diffusion coefficient. Eqn. $(11)[6,22]$ for the anode biofilm porosity $\theta$ can be written as:

$$
\theta=1-\sum_{\mathrm{i}=1}^{\mathrm{n}} \frac{\mathrm{c}_{\mathrm{B}, \mathrm{i}}}{\rho_{\mathrm{B}, \mathrm{i}}}
$$

where $c_{B, i}$ is the concentration of the biomass species $i$ in the biofilm (the model assumed that only exoelectrogens exist in the anode biofilm) $(\mathrm{g} / \mathrm{L}), \rho_{\mathrm{B}, \mathrm{i}}$ is an individual microbe's density (defined as the mass divided by the volume of the cell) $(\mathrm{g} / \mathrm{L})$.

Since the cathodic potential is known in this model, the values of anodic potential can be obtained by the electrochemical first principle relations [12]. The anodic activation overpotential is calculated by Eqn. (12).

$$
\left|\eta_{\text {act }, \mathrm{A}}\right|=\mathrm{E}_{\mathrm{A}}-\mathrm{E}_{\mathrm{A}}^{0}-\left|\eta_{\text {con,A }}\right|-\mathrm{IR}_{\mathrm{int}}
$$


where the $\eta_{\text {act, } \mathrm{A}}$ is the anodic activation overpotential $(\mathrm{V}), \eta_{\mathrm{con}, \mathrm{A}}$ is the anodic concentration overpotential $(\mathrm{V}), \mathrm{E}_{\mathrm{A}}{ }^{0}$ is the anode open circuit potential $(\mathrm{V}), \mathrm{I}$ is the current $(\mathrm{A}), \mathrm{R}_{\mathrm{int}}$ is the internal resistance $(\Omega)$. The boundary condition of the anodic potential is calculated by the known cathode potential and cell voltage, shown in Eqn. (13).

$$
\mathrm{E}_{\mathrm{A}, \text { boundary }}=\mathrm{E}_{\mathrm{C}}-\mathrm{V}_{\text {cell }}
$$

where $\mathrm{E}_{\mathrm{c}}$ is the known cathodic potential $(\mathrm{V}), \mathrm{V}_{\text {cell }}$ is the cell voltage $(\mathrm{V})$; the cell voltage relation is:

$$
\mathrm{V}_{\text {cell }}=\mathrm{IR}_{\mathrm{ext}}
$$

where $\mathrm{R}_{\mathrm{ext}}$ is the loaded external resistance $(\Omega)$.

Cathode Assumptions. - In the cathode steady state model, a fully matured cathode biofilm was considered; cathode biofilms are much thicker, assumed to be $1.0 \mathrm{~mm}$ in the one chamber MFC reactor, than anode biofilms, strongly affecting system performance [9]. It is noted that cathode biofilm thickness can differ considerably among experiments, depending on cell conditions [23]. The acetate is again the electron donor in the bulk liquid, obeying a Dirichlet boundary condition with a concentration of $1.0 \mathrm{~g} / \mathrm{L}$. Two types of bacteria were assumed to be present in the cathode biofilm: autotrophic aerobic bacteria $(\mathrm{AAB})$ and heterotrophic aerobic bacteria $(\mathrm{HAB})$. The $\mathrm{AAB}$ are biological catalysts for the ORR at the cathode, acting as electron acceptors for the external circuit. The HAB do not depend on the circuit for electrons, but they influence the mass transport and hydroxide distribution in the cathode. For the cathode half-cell model, the anode electrical potential was kept constant.

Cathode Steady State Model. - The one-dimensional cathodic steady state model was constructed by $\mathrm{C}++$ programming on a Linux system leading to polarization and power density curves that were compared with experimental data. The two-dimensional steady state model was 
built using COMSOL software to analyze the ORR in the biocatalyst and metal catalyst layers. It is noted that both biocatalyst and metal catalyst layers change in performance over time; this behavior was not included here. Transport in the cathode is more complex than the anode, with the various material layers affecting transport throughout the cathode. The cathode in this model was separated into 4 layers as shown in Fig. 2: the PTFE-coated diffusion layer, the carbon cloth, the Pt/C catalyst layer, and the biofilm. The carbon cloth and Pt/C catalyst layers were both saturated with liquid while the PTFE layer was water-proof and electrically insulating. A representative sample of the layered cathode was imaged by scanning electron microscope (SEM); the cathode layer thickness values used in the model were based on image analysis of the micrographs. Table 1 shows the thickness of the cathode layers.

Table 1. Thickness of each layer at cathode cross section

\begin{tabular}{ccc}
\hline & Averaged Thickness $(\boldsymbol{\mu m})$ & Standard Deviation $(\boldsymbol{\mu m})$ \\
\hline PTFE diffusion layer & 23 & 3 \\
Carbon cloth & 173 & 13 \\
Pt/C Catalyst layer & 33 & 6 \\
\hline
\end{tabular}

The ORR occurs in the metal catalyst layer and cathodic biofilm in the cathode model. Local reaction stoichiometry is defined by the electron distribution between two pathways: most electrons are consumed in the platinized ORR while the remaining electrons are used to support synthesis of autotrophic bacteria in the cathode biofilm.

a) Metal catalyst: Pt/C catalyst layer 
The cathode Pt/C catalyst layer supports the ORR, as shown in Eqn. [2]. The electron balance in the cathode can be described via the following equations [3]:

$$
\begin{gathered}
0=\frac{\partial \mathrm{i}_{\mathrm{C}}}{\partial \mathrm{x}}+\left(\alpha_{\mathrm{O} 2} \mathrm{~F}\right) \mathrm{r}_{\mathrm{O} 2, \mathrm{C}} \\
0=\frac{\partial \mathrm{i}_{\mathrm{C}}}{\partial \mathrm{x}}-\left(\alpha_{\mathrm{OH}} \mathrm{F}\right) \mathrm{r}_{\mathrm{OH}, \mathrm{C}} \\
\varepsilon_{\mathrm{C}} \mathrm{I}=\mathrm{A}_{\mathrm{S}} \int_{0}^{\mathrm{L}_{\mathrm{Cl}}} \mathrm{di}_{\mathrm{C}}
\end{gathered}
$$

where $i_{C}$ is the cathode current density $\left(\mathrm{A} / \mathrm{m}^{2}\right), \alpha_{\mathrm{O} 2}$ is the electron equivalence to oxygen (mol $\mathrm{e}^{-}$ $\left./ \mathrm{O}_{2} \mathrm{~mol}\right), \alpha_{\mathrm{OH}}$ is the electron equivalence to hydroxide $\left(\mathrm{mol} \mathrm{e}^{-} / \mathrm{OH}^{-} \mathrm{mol}\right), \varepsilon_{\mathrm{C}}$ is the fraction of electrons utilized by the metal catalyst, I is the total external current of the MFC (A), As is the cross sectional area of the cathode $\left(\mathrm{m}^{2}\right)$, and $\mathrm{L}_{\mathrm{cl}}$ is the thickness of metal catalyst $(\mathrm{m})$.

b) Biological catalyst: autotrophic aerobic bacteria

For the $\mathrm{AAB}$, which depends on $\mathrm{CO}_{2}$ and $\mathrm{O}_{2}$ concentrations, the cathode was considered to be the electron donor, thus no donor reaction is specified. The electron acceptor reaction $\left(\mathrm{R}_{\mathrm{a}}\right)$ and cell synthesis reaction $\left(\mathrm{R}_{\mathrm{c}}\right)$ are shown in Eqn. (18) and Eqn. (19).

$$
\begin{aligned}
& \mathrm{R}_{\mathrm{a}}: \frac{1}{4} \mathrm{O}_{2}+\frac{1}{2} \mathrm{H}_{2} \mathrm{O}+\mathrm{e}^{-} \rightarrow \mathrm{OH}^{-} \quad \Delta \mathrm{G}^{0^{\prime}}=-78.72 \mathrm{~kJ} / \mathrm{e}^{-} \mathrm{eq} \\
& \mathrm{R}_{\mathrm{c}}: \frac{1}{5} \mathrm{CO}_{2}+\frac{1}{20} \mathrm{HCO}_{3}^{-}+\frac{1}{20} \mathrm{NH}_{4}^{+}+\frac{11}{20} \mathrm{H}_{2} \mathrm{O}+\mathrm{e}^{-} \rightarrow \frac{1}{20} \mathrm{C}_{5} \mathrm{H}_{7} \mathrm{O}_{2} \mathrm{~N}+\mathrm{OH}^{-}
\end{aligned}
$$

where the catabolic reaction $\Delta \mathrm{G}_{\mathrm{r}}{ }^{0}$ is the difference between the electron donor and the electron acceptor and is assumed to be $\Delta \mathrm{G}_{\mathrm{r}}^{0^{\prime}}=-78.32 \mathrm{~kJ} / \mathrm{e}^{-}$eq, while the carbon source (cathode) conversion to pyruvate is $\Delta \mathrm{G}_{\mathrm{p}}{ }^{{ }^{\prime}}=35.09 \mathrm{~kJ} / \mathrm{e}^{-}$eq, and conversion of pyruvate into biomass $\left(\mathrm{C}_{5} \mathrm{H}_{7} \mathrm{O}_{2} \mathrm{~N}\right)$ is $\Delta \mathrm{G}_{\mathrm{pc}}{ }^{{ }^{\prime}}=18.81 \mathrm{~kJ} / \mathrm{e}^{-}$eq. An electron and energy balance between anabolism and catabolism of AAB is shown in Eqn. (20) [17]:

$$
\frac{\mathrm{f}_{\mathrm{e}}^{0}}{\mathrm{f}_{\mathrm{s}}^{0}}=\frac{-\left(\frac{\Delta \mathrm{G}_{\mathrm{p}}^{0^{\prime}}}{\sigma^{\mathrm{n}}}+\frac{\Delta \mathrm{G}_{\mathrm{pc}}^{0^{\prime}}}{\sigma}\right)}{\sigma \Delta \mathrm{G}_{\mathrm{r}}^{0^{\prime}}}
$$


where $\mathrm{f}_{\mathrm{e}}^{0}$ is the fraction of electrons directed by $\mathrm{AAB}$ from the cathode to $\mathrm{O}_{2}, \mathrm{f}_{\mathrm{s}}^{0}$ is the fraction of electrons that go from the cathode to biomass $\left(\mathrm{f}_{\mathrm{e}}^{0}+\mathrm{f}_{\mathrm{s}}^{0}=1\right), \sigma$ is the efficiency of the energy transfer (typical value of $0.6[17]$ ), and $\mathrm{n}$ is an influence factor that equals 1 if $\Delta \mathrm{G}_{\mathrm{p}}{ }^{{ }^{\prime}}>0$ or -1 if $\Delta \mathrm{G}_{\mathrm{p}}^{{ }^{\prime}}<0\left(\mathrm{n}=1\right.$ in this situation because $\Delta \mathrm{G}_{\mathrm{p}}^{{ }^{\prime}}{ }^{\prime}=35.09 \mathrm{~kJ} / \mathrm{e}^{-}$eq $)$. For this reaction, the fraction $\mathrm{f}_{\mathrm{e}}^{0} / \mathrm{f}_{\mathrm{s}}^{0}$ equals to 1.912 , so $\mathrm{f}_{\mathrm{e}}^{0}=0.657$ and $\mathrm{f}_{\mathrm{s}}^{0}=0.343$. Based on the energy and electron transfer analysis of AAB growth on the cathode, the resultant stoichiometric equation is shown below:

$$
\begin{aligned}
& 0.16425 \mathrm{O}_{2}+0.0686 \mathrm{CO}_{2}+0.01715 \mathrm{NH}_{4}^{+}+0.01715 \mathrm{HCO}_{3}^{-}+0.51715 \mathrm{H}_{2} \mathrm{O}+\mathrm{e}^{-} \rightarrow \\
& 0.01715 \mathrm{C}_{5} \mathrm{H}_{7} \mathrm{O}_{2} \mathrm{~N}+\mathrm{OH}^{-}
\end{aligned}
$$

From Eqn. (20), AAB biomass yield $\mathrm{Y}_{\mathrm{B}, \mathrm{AAB}}$ is $0.1044(\mathrm{~mol} \mathrm{AAB}) /\left(\mathrm{mol} \mathrm{O}_{2}\right), \mathrm{AAB}$ hydroxide yield $\mathrm{Y}_{\mathrm{OH}, \mathrm{AAB}}$ is $6.088\left(\mathrm{~mol} \mathrm{OH}^{-}\right) /\left(\mathrm{mol} \mathrm{O}_{2}\right)$, and the electron equivalence of oxygen $\mathrm{Y}_{\mathrm{e}-, \mathrm{AAB}}$ in $\mathrm{AAB}$ reaction is $6.088\left(\mathrm{~mol} \mathrm{e}^{-}\right) /\left(\mathrm{mol} \mathrm{O}_{2}\right)$. The reaction rate of biomass and hydroxide can then be calculated:

$$
\begin{aligned}
r_{B, A A B} & =-Y_{B, A A B} r_{O 2, A A B} \\
r_{O H, A A B} & =-Y_{O H, A A B} r_{O 2, A A B}
\end{aligned}
$$

c) Heterotrophic Aerobic Bacteria

When only acetate serves as the carbon source in the MFC reactor, the electron donor reaction $\left(R_{d}\right)$, electron acceptor reaction $\left(R_{a}\right)$, and the cell synthesis reaction $\left(R_{c}\right)$ for HAB are shown in Eqn. (24), Eqn. (25) and Eqn. (26), respectively.

$$
\begin{aligned}
& \mathrm{R}_{\mathrm{d}}: \frac{1}{8} \mathrm{CH}_{3} \mathrm{COO}^{-}+\frac{3}{8} \mathrm{H}_{2} \mathrm{O} \rightarrow \frac{1}{8} \mathrm{CO}_{2}+\frac{1}{8} \mathrm{HCO}_{3}^{-}+\mathrm{H}^{+}+\mathrm{e}^{-} ; \Delta \mathrm{G}^{0^{\prime}}=-27.04 \mathrm{~kJ} / \mathrm{e}^{-} \mathrm{eq} \\
& \mathrm{R}_{\mathrm{a}}: \frac{1}{4} \mathrm{O}_{2}+\mathrm{H}^{+}+\mathrm{e}^{-} \rightarrow \frac{1}{2} \mathrm{H}_{2} \mathrm{O} \\
& \mathrm{R}_{\mathrm{c}}: \frac{1}{5} \mathrm{CO}_{2}+\frac{1}{20} \mathrm{HCO}_{3}^{-}+\frac{1}{20} \mathrm{NH}_{4}^{+}+\mathrm{H}^{+}+\mathrm{e}^{-} \rightarrow \frac{1}{20} \mathrm{C}_{5} \mathrm{H}_{7} \mathrm{O}_{2} \mathrm{~N}+\frac{9}{20} \mathrm{H}_{2} \mathrm{O}
\end{aligned}
$$


Based on Eqn. (24) and (25), the total energy transfer between acetate oxidation and oxygen reduction is $\Delta \mathrm{G}_{\mathrm{r}}^{0^{\prime}}=-105.36 \mathrm{~kJ} / \mathrm{e}^{-}$eq. Energy for acetate to pyruvate conversion $\left(\Delta \mathrm{G}_{\mathrm{p}}{ }^{0^{\prime}}\right)$ should be the sum of the energy of reaction for the donor reaction $\left(\Delta \mathrm{G}^{0^{\prime}}=-27.04 \mathrm{~kJ} / \mathrm{e}^{-}\right.$eq) in Eqn. (24) and the pyruvate production reaction $\left(35.09 \mathrm{~kJ} / \mathrm{e}^{-} \mathrm{eq}\right)$, therefore $\Delta \mathrm{G}_{\mathrm{p}}{ }^{\prime}$ is $8.05 \mathrm{~kJ} / \mathrm{e}^{-}$eq. Finally, conversion of pyruvate into biomass $\left(\mathrm{C}_{5} \mathrm{H}_{7} \mathrm{O}_{2} \mathrm{~N}\right) \Delta \mathrm{G}_{\mathrm{pc}}{ }^{\prime}$ is $18.81 \mathrm{~kJ} / \mathrm{e}^{-}$eq. Based on Eqn. (20), $\mathrm{f}_{\mathrm{e}}{ }^{0}$ can be calculated to be 0.415 and $\mathrm{f}_{\mathrm{s}}^{0}$ can be calculated to be 0.585 , giving the following calculated stoichiometric relation for HAB growth on the cathode:

$$
\begin{array}{rl}
\mathrm{CH}_{3} \mathrm{COO}^{-}+0.83 \mathrm{O}_{2}+0 & 0.234 \mathrm{NH}_{4}^{+}+0.064 \mathrm{H}_{2} \mathrm{O} \\
\rightarrow & 0.234 \mathrm{C}_{5} \mathrm{H}_{7} \mathrm{O}_{2} \mathrm{~N}+0.064 \mathrm{CO}_{2}+0.766 \mathrm{HCO}_{3}^{-}
\end{array}
$$

By calculating the biochemical reaction for the cathode biofilm, the resultant HAB biomass yield $\mathrm{Y}_{\mathrm{B}, \mathrm{HAB}}$ is $0.234(\mathrm{~mol} \mathrm{HAB}) /\left(\mathrm{mol}\right.$ Acetate), and $\mathrm{HAB}$ oxygen yield on acetate $\mathrm{Y}_{\mathrm{O}, \mathrm{HAB}}$ is $0.83\left(\mathrm{~mol} \mathrm{O}_{2}\right) /(\mathrm{mol}$ Acetate). The reaction rate of biomass and oxygen can be calculated by Eqn. (28) and Eqn. (29).

$$
\begin{gathered}
r_{\mathrm{B}, \mathrm{HAB}}=-Y_{\mathrm{B}, \mathrm{HAB}} r_{\mathrm{Ac}, \mathrm{HAB}} \\
r_{\mathrm{O} 2, \mathrm{HAB}}=Y_{\mathrm{O} 2, \mathrm{H}} r_{\mathrm{Ac}, \mathrm{HAB}}
\end{gathered}
$$

Acetate and oxygen are both reactants in the generation of new biomass in the cathode biofilm. Since electric field migration has been shown in the anode model to have only minor influence, and fluid flow in the reactor was neglected, the form of the governing equation for the cathode only considered the diffusion term, described as:

$$
\frac{\partial c_{s}}{\partial t}=\nabla\left(D_{s} \nabla c_{s}\right)+r_{c_{s}}
$$


The cathode biofilm was assumed to have fully matured with a constant biofilm thickness. Therefore, both the $\mathrm{HAB}$ concentration and $\mathrm{AAB}$ concentration were constants in the cathode biofilm.

Experimental description.

Polarization experiments were conducted with multiple single chamber air-cathode MFC reactors described elsewhere [24]. The MFC reactor was operated in a batch mode with no stirring, thus the liquid was stagnant except during growth medium replacement. Two types of anode material were used: for the analysis of power output and anodic limitations, the anode material was carbon paper (Plain Carbon Paper, BASF) due to its constant thickness and simplified modeling variables in the anodic model. For the analysis of the cathodic performance, the anode was changed to a carbon brush as that yields better, more stable performance. Wetproofed carbon paper (30\% Teflon Treated Carbon Cloth, Fuel Cell Earth) with PTFE diffusion layers and $0.5 \mathrm{mg}-\mathrm{Pt} / \mathrm{cm}^{2}$ platinum catalyst layer served as the cathode [26]. MFCs were inoculated with effluent from a mature MFC reactor generating constant peak power. Following inoculation, the MFCs were operated in batch mode with a growth medium comprised of $50 \mathrm{mM}$ phosphate buffer, $1.0 \mathrm{~g} / \mathrm{L}$ sodium acetate as the electron donor [27], and $1000 \Omega$ external resistance until achieving a stable cell voltage (ca. $0.5 \mathrm{~V}$ ). Polarization data were collected by changing the external resistance every 20 mins while recording cell voltage and electrode potentials [28]. Single electrode potentials were measured against an in-situ reference electrode ( $\mathrm{Ag} / \mathrm{AgCl}$ reference electrode, $\mathrm{BASi}$ ) vertically inserted from the top of the reactor into the bulk liquid approximately $1.0 \mathrm{~cm}$ from the solution side of the anode surface and $2.5 \mathrm{~cm}$ from the solution side of the cathode surface. This placement, while subject to some influence by the potential gradient across the bulk liquid achieved a stable reference potential over the course of 
experiments [25], this is routinely done in studies using single chamber air-cathode MFCs as there is no alternative with this reactor configuration. External current was calculated based on Ohm's law and current/power densities were based on projected cathode surface area.

\section{Results and Discussion}

Comparison of the ionic diffusion and electric migration in anode steady state model.

The polarization and power density curves, shown in Fig. 3, illustrate the impact of including the electric field on mass transport to the MFC performance. The simulation results of mass transport (including both diffusion and electric field) fit well with the experimental profile, with polarization curve average deviation less than $2.20 \%$. The simulation results of mass transport without the influence of field-induced migration (i.e., diffusion only) produced similar power density and polarization curves based on the anode model, but with a consistently underestimated power density (by an average 1.92\%) at every steady state point compared with the two-part mass transport case (combined diffusion and electric field). Thus, inclusion of the electric field has small influence on the accuracy of the model, indicating electric field-induced migration to be minor compared to concentration-driven diffusion. Other anode modeling work neglected the electric field influence on the mass transport $[2,16]$; this work is consistent with and shows the applicability of that assumption.

Power output prediction and cathodic limitations analysis for the MFC cathode system.

Following completion of the anodic half-cell model, the cathode model that includes contributions from Pt metal and biological catalysts was also constructed. Sources of cathode overpotential, including electrochemical activation, ohmic resistance, mass transport losses, and substrate crossover, have recently been studied and found to have significant influence on system performance [11]. In this cathode model the anode potential was taken from experimental data 
(the red anodic potential line shown in Fig. 4 a)), allowing the anode overpotential to be obtained at every external resistance, steady-state situation. It is apparent that the simulated cathode potentials are comparable to the experimental cathode potentials (Fig. 4 a)) and that, in the operating cell, the cathode overpotential increases twice as much as the anode overpotential with increasing current density. The largest deviation between polarization curves is $7.7 \%$ (Fig. 4 a)), and the largest deviation between power density curves is $8.8 \%$ (Fig. 4 b)).

The cathode model was formulated to delineate the various sources of overpotential associated with driving current. Specifically, concentration overpotential, activation overpotential, and ohmic overpotential were all separated; bulk liquid ohmic drop was also considered. Shown in Fig. 5, the activation overpotential is the primary loss for a MFC system at low current density. The ohmic overpotential linearly grows as the current density increases, and both the ohmic overpotential and activation overpotential dominated voltage loss in the operating MFC. Concentration overpotential is a very minor component of the cathode total overpotential; this supports the assumption of neglecting mass transport limitations in some papers $[3,16]$. In light of these findings, minimizing overpotentials in the cathode provides the most efficient path to improving MFC performance.

Comparison of the performance of metal catalyst and biocatalyst in cathode.

Direct comparison of metal catalyst and biocatalyst performance in the cathode is rare in the literature [11]. When a biocatalyst and Pt catalyst are in the same system, others have found that the biocatalyst contribution to oxygen reduction is minor compared to that of the Pt metal catalyst [8]. The cathode steady state model allows a clear comparison of the performance of the metal catalyst and biocatalyst. Before the simulation, it was assumed that the cathodic biofilm 
was mature and that the Pt catalysts did not degrade; thus, the resultant power density was stable. Fig. 6 shows the modeling results of the polarization curve and the power density for both the biocatalyst-only cathode configuration and the biocatalyst with $\mathrm{Pt}$ metal catalyst cathode configuration. As expected, the biocatalyst-only cathode showed much poorer performance than the combined biocatalyst and metal catalyst. The highest power density for the biocatalyst-only simulation was $21 \mathrm{~mW} / \mathrm{m}^{2}$ while the highest power density for the biocatalyst with metal catalyst simulation was $239 \mathrm{~mW} / \mathrm{m}^{2}$. Thus, the biofilm only contributed $8.8 \%$ of the total power in the combined catalyst simulation. $\mathrm{Pt} / \mathrm{C}$ as the cathode material only produces $0.55 \mathrm{~mW} / \mathrm{\$}$, thus this material greatly increases the cost of an MFC system [29]. On the other hand, if the fraction of $\mathrm{AAB}$ in cathode biofilm could be increased, the $\mathrm{AAB}$ would improve the power output and potentially decrease the cost for cathode materials.

The multiphysics modeling software COMSOL was adopted into the analysis to aid in better describing the catalyst performance. In Fig. 7, $\mathrm{pH}$ is used as an indicator of cathode activity; $\mathrm{pH}$ would be much higher in a situation where the ORR happens more rapidly due to the production of $\mathrm{OH}^{-}$. Fig. 7 a) and Fig. 7 b) show COMSOL model results comparing the pH distribution of $\mathrm{Pt} / \mathrm{C}$ catalyst and the biofilm cathode (model parameters and variables are shown in the Appendix). Both systems are $1.0 \mathrm{~mm} \times 1.0 \mathrm{~mm}$ sectional views of the cathode, comprised of identical reactor structure and operating conditions thus the difference only resulted from the catalyst. It is apparent that the $\mathrm{pH}$ in the $\mathrm{Pt} / \mathrm{C}$ catalyzed cathode is much higher than in the $\mathrm{AAB}$ biocatalyst cathode; this indicates that the metal catalyst is a much more effective catalyst since the ORR product is hydroxide. Because this work focused on the cathode, the bulk liquid pH was maintained at 7.08 during simulation, instigating the rapid drop in $\mathrm{pH}$ at the far left of each plot in Fig. 7. 


\section{Conclusions}

In this work, a systematic series of equations to describe the physical, chemical, biological, and electrochemical phenomena in an air cathode MFC was established. A steady state anode model was utilized to describe the diffusion and electric field in the ions transport. The electric field-induced migration has a minor impact on MFC performance based on the anodic model, thus the electric field can be neglected in the mass transport analysis. A steady state cathode model was also developed, with specific interest in $\mathrm{pH}$ distribution as an indicator of catalyst activity, which ultimately described chemical substance transport through the various cathode layers. The cathode overpotential was separated into kinetic, ohmic, and concentrationdependent sources of polarization. The cathode was found to dominate the MFC overpotential at all operating currents, indicating that all three contributions to overpotential are more limiting in the cathode. Such insight provides guidance for the greatest opportunity for improvement in the system. Throughout the range of current density, activation and ohmic overpotentials dominated the full cell performance. Finally, the cathode model predicted that, while both bacteria and Pt perform oxygen reduction in the cathode, the bacterial contribution to current was less than $10 \%$. Thus, the primary contribution of the cathode biofilm bacteria is to prevent oxygen from crossing over to the anaerobic anode.

\section{Acknowledgments}

This research was supported by the US Army Research Office, contract number: W911NF-11-10531.

\section{List of Symbols}

$A_{C} \quad$ cathode active surface area, $m^{2}$ 
$b_{\text {decay }}$ decay coefficient

c molar concentration, $\mathrm{mol} / \mathrm{L}$

$D$ diffusion coefficient, $\mathrm{m}^{2} / \mathrm{s}$

$E_{A}^{0} \quad$ anode open circuit potential, $V$

$f_{D} \quad$ fraction of cells contributing to debris

$f_{e}^{0} \quad$ fraction of energy gain (catabolism)

$f_{s}^{0} \quad$ fraction of energy cost for cell synthesis (anabolism)

F Faraday constant, $96485 \mathrm{C} / \mathrm{mol}$

$i$ current density, $A / m^{2}$

$i_{\text {lim }}$ limited current density, $A / m^{2}$

$I$ current, $A$

$k_{\text {det }}$ detachment velocity constant, $g / \mathrm{m}^{4} s$

$K_{A c}$ half-maximum-rate acetate concentration, $\mathrm{mol} / \mathrm{L}$

$K_{O x}$ half-maximum-rate oxygen concentration, $\mathrm{mol} / \mathrm{L}$

$L \quad$ layer thickness, $m$

M Molar mass, $\mathrm{g} / \mathrm{mol}$

$q_{A c, \max }$ maximum specific rate of acetate utilization, ( $g$ acetate)/( $g$ acetate)day

$r$ reaction rate, $\mathrm{mol} / \mathrm{m}^{2} \mathrm{~s}$

$R$ reaction equation

$u_{B} \quad$ biofilm displacement velocity, $\mathrm{m} / \mathrm{s}$

$u_{\text {det }}$ biofilm detachment velocity, $\mathrm{m} / \mathrm{s}$

Greek 
$\alpha$ the electron equivalence, $\left(\mathrm{mol} \mathrm{e}^{-}\right) / \mathrm{mol}$

$\varepsilon$ path fraction of electrons

$\rho$ density, $\mathrm{g} / \mathrm{cm}^{3}$

$\sigma$ energy transfer efficiency in anabolic reaction

$\sigma_{b i o, A}$ anode biofilm conductivity, $S / m$

$\theta$ Porosity

$\eta_{a c t, K A}$ charge transfer coefficient of anodic activation overpotential, $V$

Subscripts

a electron acceptor

$A A B$ autotrophic aerobic biomass

Ac acetate

$A R B \quad$ Anode respiration biomass

$B$ biomass

c cell synthesis

cl catalyst layer

C cathode

$d$ electron donor

decay biomass decay

$H A B$ heterotrophic aerobic biomass

ox oxidized substance

02 oxygen

$\mathrm{OH}$ hydroxide

red reduced substance 
$S$ substance

8

12

13

14

15

16

17

18

19

20

21

22

23

24

25

26

27

28

29

30

31

32

33

34

35

36

37

38

39

40

41

42

43

44

45

46

47

48

49

50

51

52

53

54

55

56

57

58

59

60

61

62

63

64

65 


\section{References}

[1] B. E. Logan, Microbial Fuel Cells, John Wiley \& Sons, Inc., Hoboken, New Jersey, 2008.

[2] C. Picioreanu, I. M. Head, K. P. Katuri, M. C. van Loosdrecht, K. Scott, Water Research, 41 (2007) 2921-2940.

[3] A. Kato Marcus, C. I. Torres, B. E. Rittmann, Biotechnology and Bioengineering, 98 (2007) 1171-1182.

[4] B. E. Rittmann, P. L. McCarty, Biotechnology and Bioengineering, 22 (1980) 2343-2357.

[5] O. Wanner, W. Gujer, Biotechnology and Bioengineering, 28 (1986) 314-328.

[6] J. B. Xavier, C. Picioreanu, M. C. van Loosdrecht, Biotechnology and Bioengineering, 91 (2005) 651-669.

[7] B. E. Logan, B. Hamelers, R. Rozendal, U. Schröder, J. Keller, S. Freguia, P. Aelterman, W. Verstraete, K. Rabaey, Environmental Science \& Technology, 40 (2006) 5181-5192.

[8] S. C. Popat, D. Ki, B. E. Rittmann, C. I. Torres, ChemSusChem, 5 (2012) 1071-1079.

[9] Y. Yuan, S. Zhou, J. Tang, Environmental Science \& Technology, 47 (2013) 4911-4917.

[10] C. Santoro, A. Agrios, U. Pasaogullari, B. Li, International Journal of Hydrogen Energy, 36 (2011) 13096-13104.

[11] H. Rismani-Yazdi, S.M. Carver, A.D. Christy, O.H. Tuovinen, Journal of Power Sources, 180 (2008) 683-694.

[12] M. M. Mench, Fuel cell engines, John Wiley \& Sons, 2008.

[13] J. T. Babauta, H. D. Nguyen, H. Beyenal, Environmental Science \& Technology, 45 (2011) 6654-6660. 
[14] H. Liu, R. Ramnarayanan, B. E. Logan, Environmental Science \& Technology, 38 (2004) 2281-2285.

[15] A. K. Marcus, C. I. Torres, B. E. Rittmann, Electrochimica Acta, 55 (2010) 6964-6972.

[16] Y. Zeng, Y. F. Choo, B.-H. Kim, P. Wu, Journal of Power Sources, 195 (2010) 79-89.

[17] C. L. Grady, G. T. Daigger, N. G. Love, C. D. Filipe, Biological Wastewater Treatment, Iwa Publishing, 2011.

[18] R. B. Bird, W. E. Stewart, E. N. Lightfoot, Transport Phenomena, John Wiley \& Sons, 2007.

[19] B. J. Kirby, Micro-and Nanoscale Fluid Mechanics: Transport in Microfluidic Devices, Cambridge University Press, 2010.

[20] C. I. Torres, A. Kato Marcus, B. E. Rittmann, Biotechnology and Bioengineering, 100 (2008) 872-881.

[21] P. Heitjans, J. Kärger, Diffusion in Condensed Matter: Methods, Materials, Models, Springer Science \& Business Media, 2006.

[22] H. Eberl, E. Morgenroth, D. Noguera, C. Picioreanu, B. Rittmann, M.v. Loosdrecht, O. Wanner, Mathematical Modeling of Biofilms, IWA Publishing, London, UK, 2006.

[23] P. D. Kiely, G. Rader, J. M. Regan, B. E. Logan, Bioresource Technology, 102 (2011) 361366.

[24] H. Liu, B. E. Logan, Environmental Science \& Technology, 38 (2004) 4040-4046.

[25] F. Zhang, J. Liu, I. Ivanov, M. C. Hatzell, W. Yang, Y. Ahn, B.E. Logan, Biotechnology and Bioengineering, 111 (2014) 1931-1939.

[26] S. Cheng, H. Liu, B. E. Logan, Electrochemistry Communications, 8 (2006) 489-494.

[27] Z. Ren, H. Yan, W. Wang, M. M. Mench, J. M. Regan, Environmental Science \& Technology, 45 (2011) 2435-2441. 
[28] J. Heilmann, B. E. Logan, Water Environment Research, 78 (2006) 531-537.

[29] Y. Yuan, S. Zhou, L. Zhuang, Journal of Power Sources, 195 (2010) 3490-3493. 


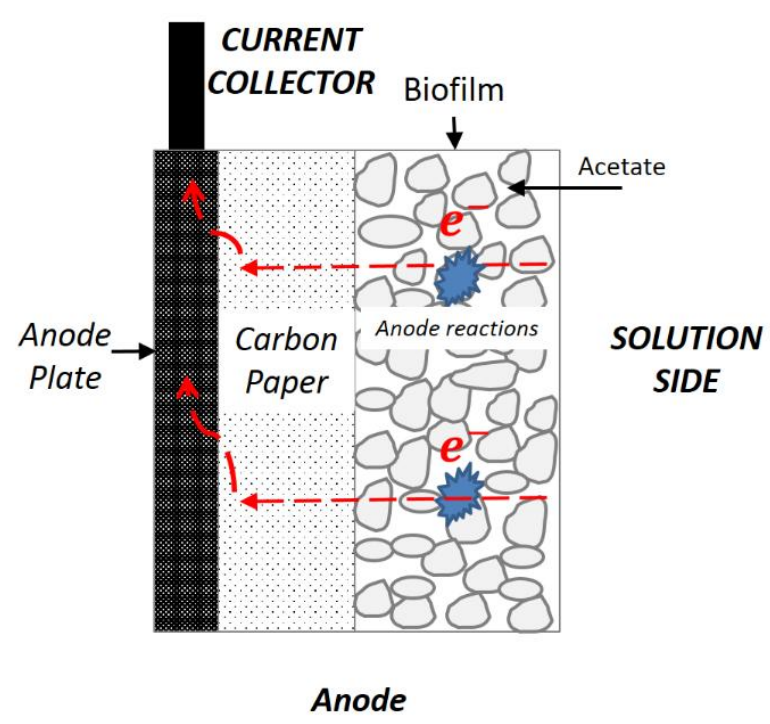

Fig. 1. Schematic of anode in MFC. 


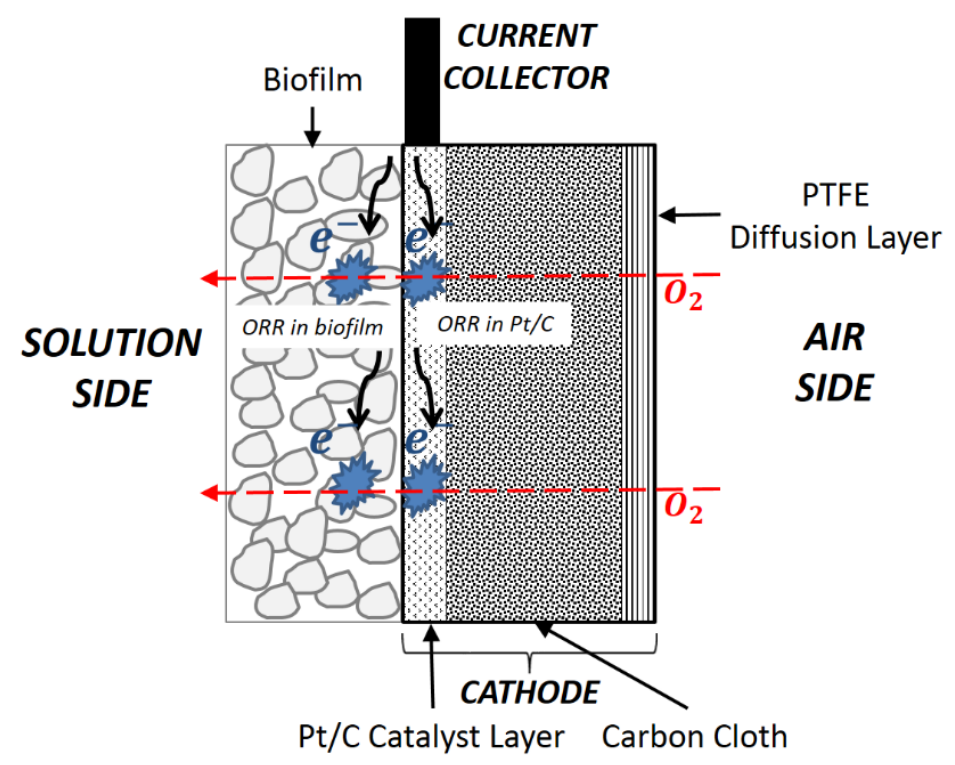

Fig. 2. Schematic of cathode in MFC. 


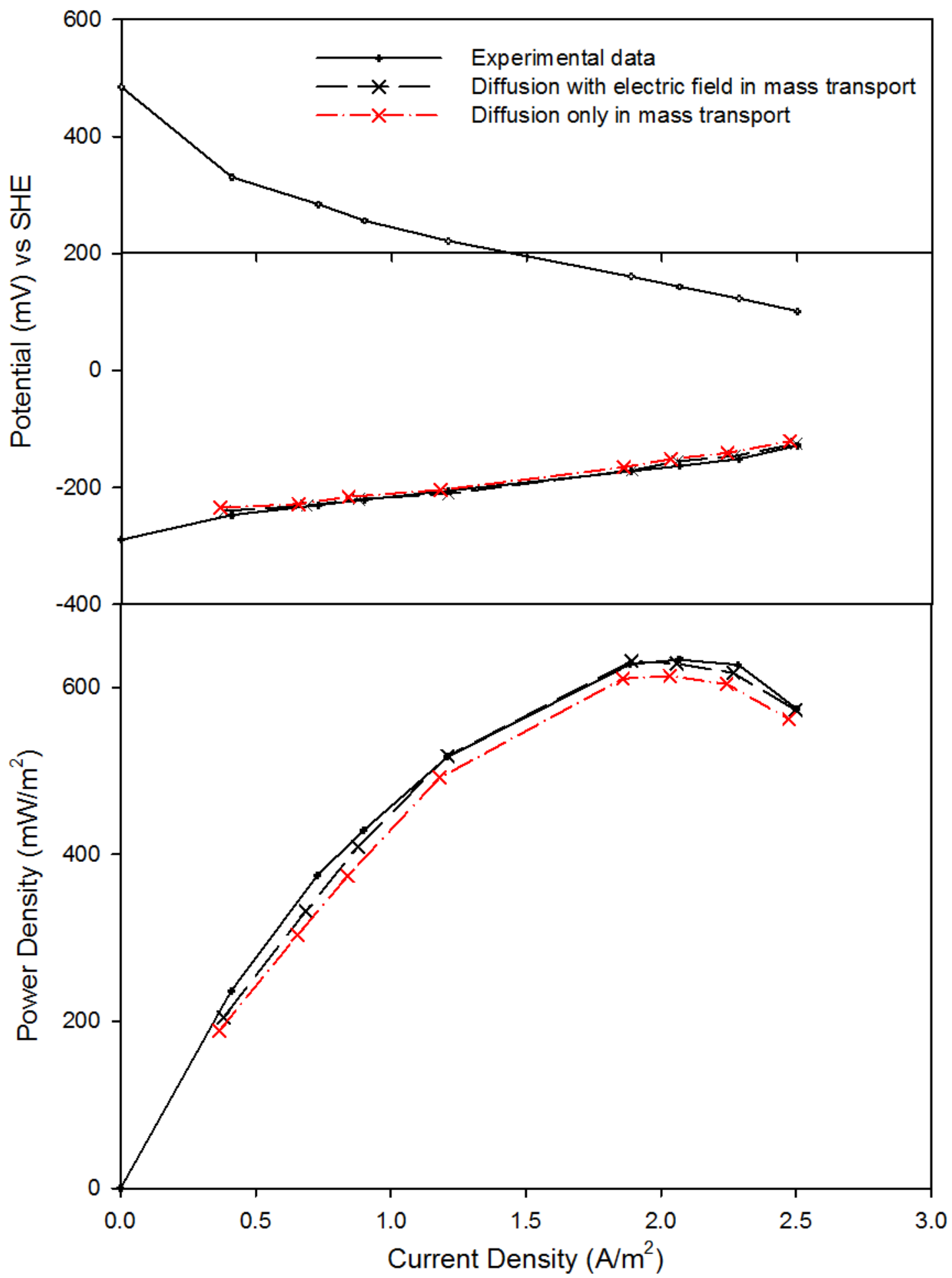

Fig. 3. Polarization and power density curves for anode model cases including only concentration-driven diffusion or diffusion and electric field-induced migration. 

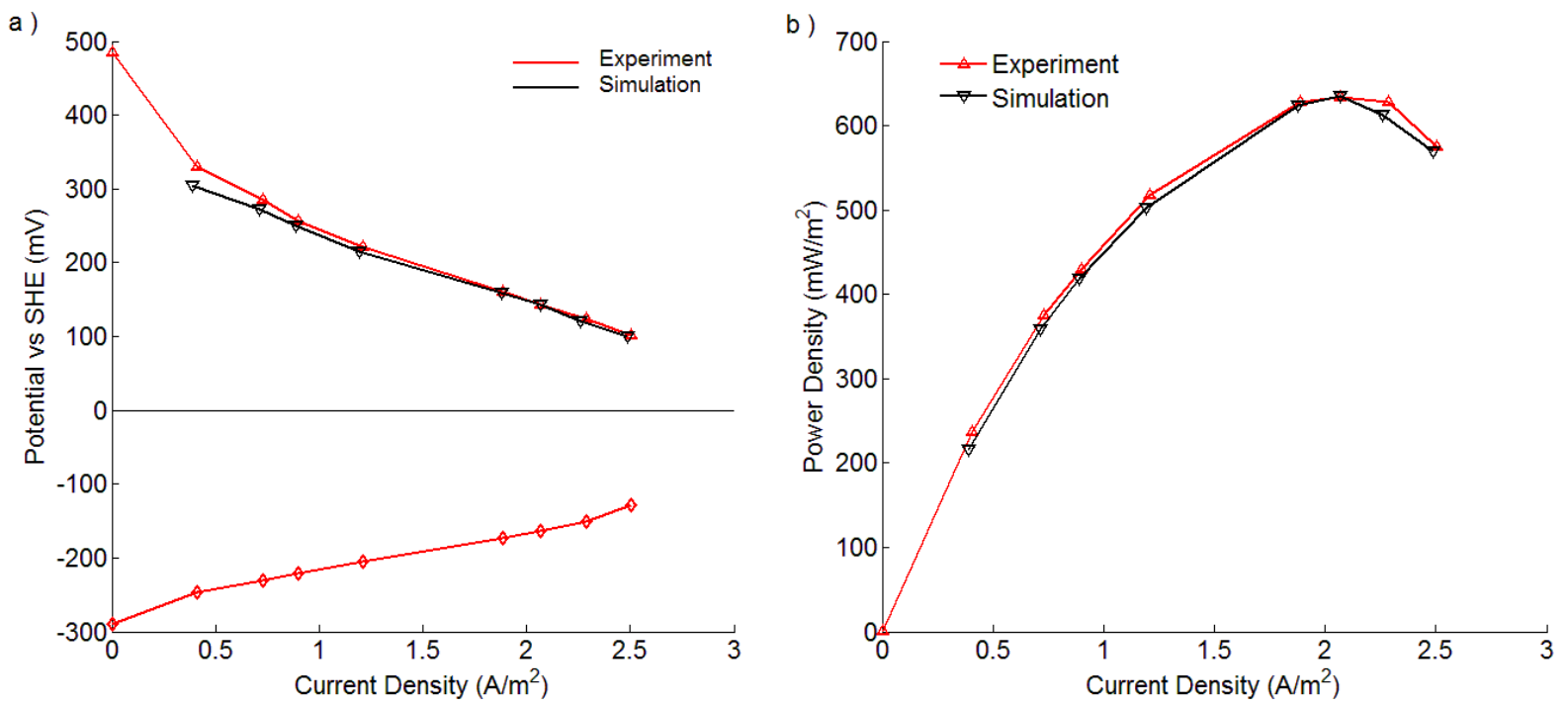

Fig. 4. Polarization curve and power density curves for the cathode model MFC system. 


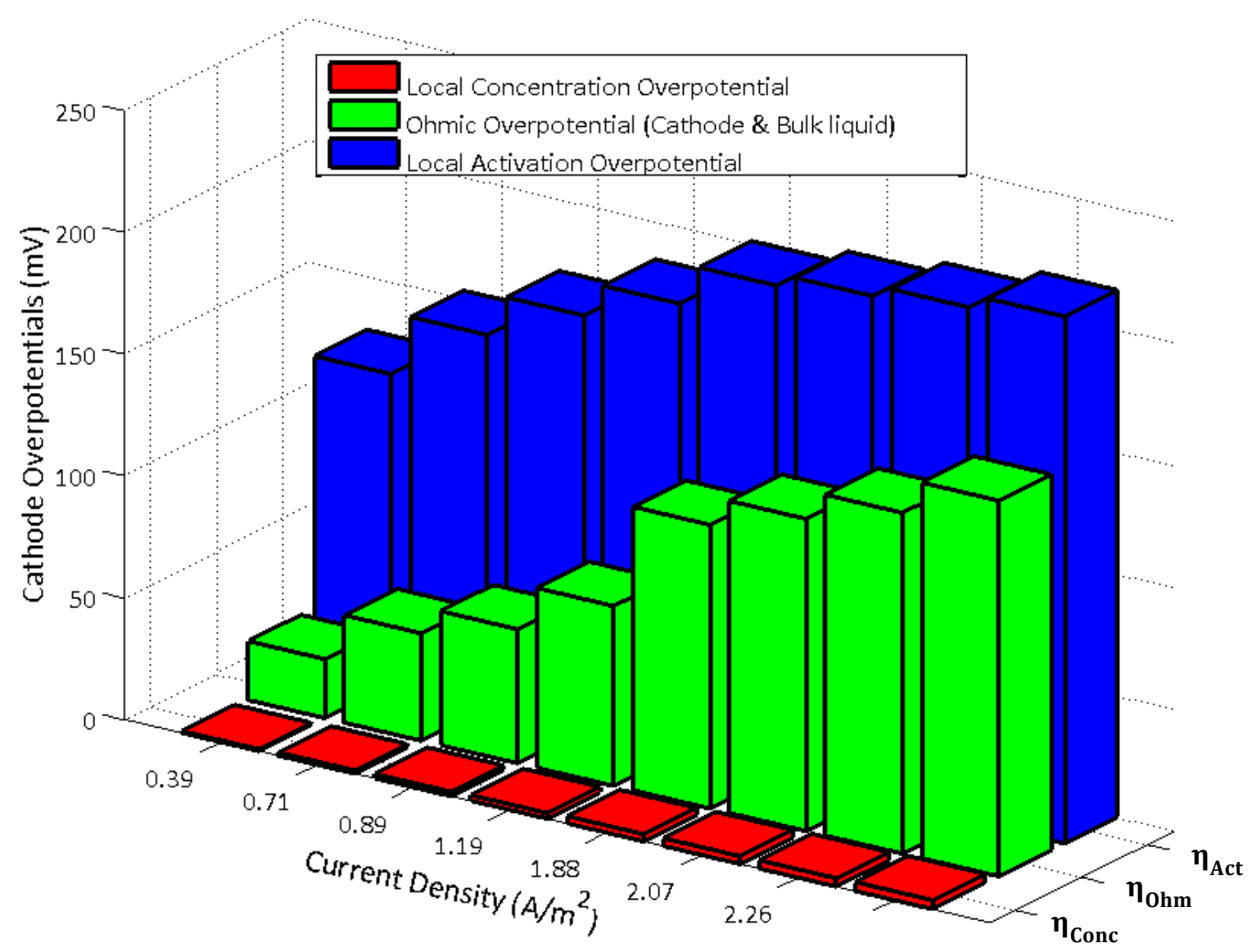

Fig. 5. Cathode overpotentials for the steady-state cathode model.

$\eta_{\text {Conc }}:$ Local concentration overpotential $(\mathrm{mV})$;

$\eta_{\text {ohm }}$ : Ohmic overpotential in cathode and bulk liquid $(\mathrm{mV})$;

$\eta_{\text {Act }}:$ Local kinetic activation overpotential $(\mathrm{mV})$. 


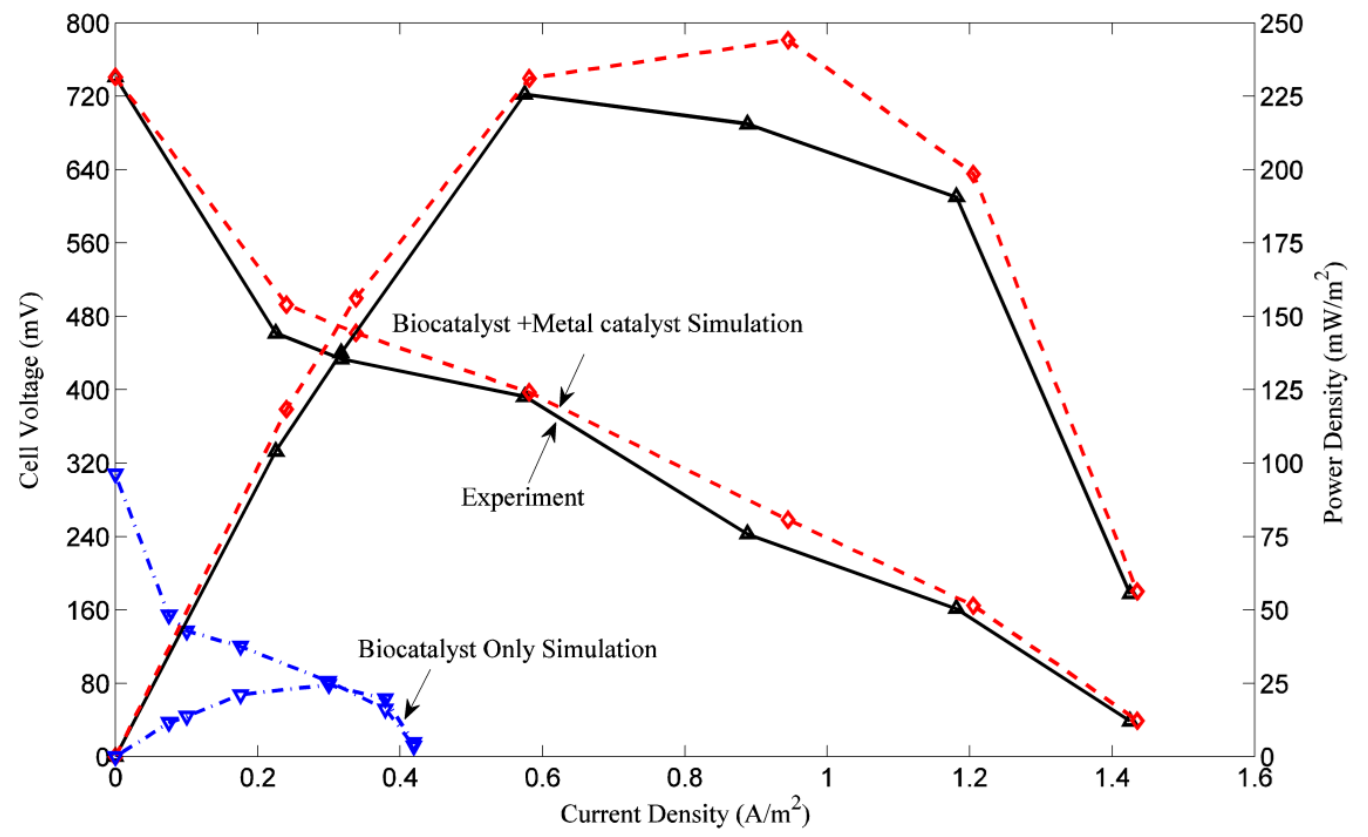

Fig. 6. Polarization and power density curve simulation results for the biocatalyst cathode and metal catalyst cathode. 


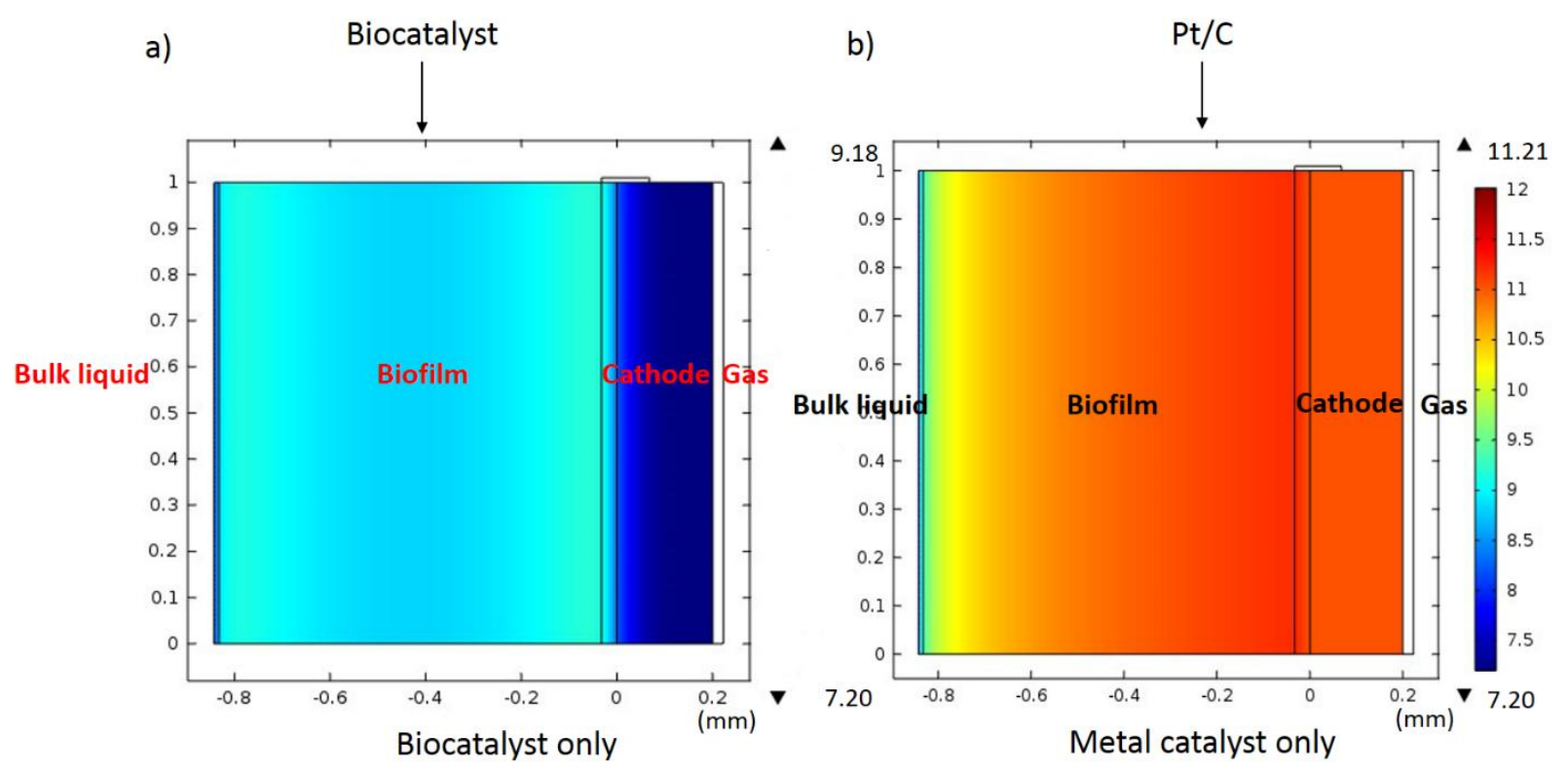

Fig. 7. $\mathrm{pH}$ distribution simulation for biocatalyst cathode and metal catalyst cathode (when external resistance is $50 \Omega$ ). 
Table 1. Thickness of each layer at cathode cross section

\begin{tabular}{ccc} 
& Averaged Thickness $(\boldsymbol{\mu m})$ & Standard Deviation $(\boldsymbol{\mu m})$ \\
\hline PTFE diffusion layer & 23 & 3 \\
Carbon cloth & 173 & 13 \\
Pt/C Catalyst layer & 33 & 6 \\
\hline
\end{tabular}




\section{Figure Captions}

Fig. 1. Schematic of anode in MFC.

Fig. 2. Schematic of cathode in MFC.

Fig. 3. Polarization and power density curves for anode model cases including only concentration-driven diffusion or diffusion and electric field-induced migration.

Fig. 4. Polarization curve and power density curves for the cathode model MFC system.

Fig. 5. Cathode overpotentials for the steady-state cathode model.

Fig. 6. Polarization and power density curve simulation results for the biocatalyst cathode and metal catalyst cathode.

Fig. 7. pH distribution simulation for biocatalyst cathode and metal catalyst cathode (when external resistance is $50 \Omega$ ). 